\title{
Book Review \\ Livelihoods and Learning: Education for All and the Marginalisation of Mobile Pastoralists. By Caroline Dyer. London: Routledge, 2014, 215 pp.; ISBN 978-0-415-58590-3 (Hardcover), 978-0-203-08390-1 (E-Book).
}

\author{
Alan Rogers \\ School of Education \& Lifelong Learning, University of East Anglia, Norwich, NR4 7TJ, UK; E-Mail: alan.rogers@uea.ac.uk
}

Submitted: 10 April 2015 | Accepted: 5 May 2015 | Published: 15 February 2016

\begin{abstract}
In this book, Caroline Dyer, whose work with education in India has been known for many years through many articles, draws together her ethnographic experience of living with the Rabari of India, and reflects on what this means for Education for All goals.
\end{abstract}

\author{
Keywords \\ marginalisation; mobile pastoralists; Education for All
}

Issue

This article is part of the issue "Educating Nomadic People", edited by Caroline Dyer (University of Leeds, UK).

(C) 2016 by the author; licensee Cogitatio (Lisbon, Portugal). This article is licensed under a Creative Commons Attribution 4.0 International License (CC BY).

UNESCO's 2010 Global Monitoring Report identified mobile pastoralists as facing "extreme educational disadvantage" and called for "urgent action" (cited in Dyer, 2014, pp, 2, 13, 180). In this book, Caroline Dyer, whose work with education in India has been known for many years through many articles, draws together her ethnographic (pp. 3, 43, 66, etc.) experience of living with the Rabari of India, and reflects on what this means for Education for All goals. The book falls into three parts-an introductory discussion of the themes of Education for All and marginalisation; a narrative of the experiences of herself and her colleague over a number of years with the Rabari, together with a follow-up visit after the earthquake of 2001; and a final discussion drawing on work in other parts of the world and different attempts to find solutions to some of the issues raised [If you are looking for a rare good news story from education in developing countries, read the account of the (still to be fully implemented) work in Kenya on pages 175-77].

The book is too rich to summarise adequately in a short review, but some key themes call for comment. One of her frameworks is that of well-being rather than purely economic goals. The "problem" of mobile pas- toralists is usually seen as the unsustainable nature of their livelihood (2), but Dyer (like others) sees this livelihood as a fully sustainable way of life which is of importance to a balanced national and global economy (pp. 3, 20, 180)-as multiple, flexible, but increasingly insecure (p. 61), facing political, socio-economic and environmental challenges (pp. 3, 31, 34, 36-37, 182). She argues that it is not the livelihoods but the mobility and the cultural practices (such as the division of labour, etc.) which make the modernisation agenda of EFA (p. 24) difficult to implement. Unlike most other "hard to reach" groups, their exclusion from education/schooling is not due to poverty but to longstanding and very strong social attitudes, which derive from colonial times (p. 46) and which see the "jungle" [like the fens of other regions] and its economies as primitive, to be cleared away, and mobile pastoralism as "culture-bound, backward and irrational" (p. 23), inimical to modernisation (in a striking phrase, "get out of sheep and goats into education" , p 136). But this is a way of life, deeply spiritual (pp. 33, 137) as well as economically viable as it adapts. And what Dyer calls "the terms of inclusion" (pp. 26, 37, 159-60) into education are often too high-for example, divided fami- 
lies with some sedentarised members in order to attend fixed-site schools with the consequent loss of labour in the travelling households. "What I seek to do in this book is to show that-in contrast with widely held expectations that inclusion in formal education acts positively on reducing poverty...and social inequalities-such education is a resource that, for mobile pastoralists, is highly contradictory and can have contrary effects.... will highlight forms of education that pastoralists have 'reason to value' (Sen, 1999) in very challenging contemporary contexts" (p. 3; see also pp. 158, $177,187)$. She argues that formal schooling can reproduce, perpetuate and even increase marginalisation or at least make it more visible (pp. 145, 163, 177).

And the losses include the disappearance of what Dyer calls "situated learning" - the traditional ways in which members of the community develop the knowledge and skills of younger members in managing their livestock and fulfilling the demands of their mobility (pp. 79-81, 99, 153, 180-182, etc.). To talk of "educational deprivation" (meaning schooling, e.g., pp. 98, 163 ) is to deny the validity and indeed vital importance of other forms of "education" by which "expertise is passed, by situated livelihood learning, from one generation to the next" (p. 99)-ways of knowing and practices which she describes in detail. The cost to the Rabari of EFA are high: "Pastoralist livelihood imperatives of mobility, situated learning and labour organisation conflict with schooling's terms of inclusion" (p. 163).

Dyer does not romanticise the Rabari-she points out that they were divided in their responses to the calls for modernisation (p. 77); in places there is an age and generation gap (pp. 151-152); some have internalised what they have been told (especially some leaders) (chapter 5; p. 135) and some wish to become "clever" in educational terms (p. 87), to participate in schooling in order to get "proper jobs" (pp. 173, 183, etc.).

Nor does she deny the significance of formal education: her studies and those of others "demonstrate that by adopting strategies of mobile provision, curricula that respond to learner demand, and flexible timings, formalised education can become an additional dimen- sion of learning for a sustainable pastoralist livelihood" (p. 183). Dyer calls for forms of "education" that "ensure that mobile pastoralists are able to access education opportunities while remaining active in pastoralism" (p. 19, italics in original; see also p. 2)-forms of education which will perhaps strengthen rather than weaken their existing economic and cultural lives (pp. $163,175-177,183$ ) and increase their resilience (p. 26) to manage the severe challenges their way of life faces from (for example) contemporary land grabs and environmental changes (pp. 184-185). (There is a useful warning that "policy interventions that support pastoralism when pastoralists would otherwise abandon it may increase rather than reduce vulnerability" (p. 36); different contexts call for different approaches).

There is much more here and some catch the eye. Mobile pastoralists are often seen as opposed to "development" but it is clear from these pages that some Rabari are keen to engage on their own terms with features of modernism which they can use within their pattern of life such as solar lanterns and mobile phones (pp. 32, 56, 73, 93). There is an analysis of the contents of the adult literacy primers in the Indian Total Literacy Campaign (p. 52). The impact of the earthquake was enormous on every aspect of life of both the mobile pastoralists and the other communities in the area.

The book is based on very wide experience of research and teaching (she reports on one occasion being "disappointed as teachers but sanguine as researchers", p. 114) and on a huge literature drawn from international sources. It is well produced, though the illustrations (important for ethnographic purposes) are unnecessarily poor with today's printing resources (the map on page 21 is indecipherable). It will remain for a long time the defining book on education and mobile pastoralism, of relevance to many parts of the world and to international policy makers on EFA; the drafters of the post-2015 education goals will find it a "must-read".

\section{Conflict of Interests}

The author declares no conflict of interests.

\section{About the Author}

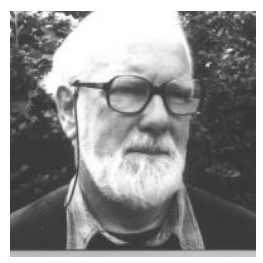

\section{Alan Rogers}

Alan Rogers is an adult educator with both university teaching and development practice experience. He was the founding Director of the Commonwealth Association for the Education and Training of Adults and of Education for Development. He currently holds Honorary Professorships at the Universities of East Anglia and Nottingham. Alan Rogers has written widely on adult learning, development and especially adult literacy in development contexts. 